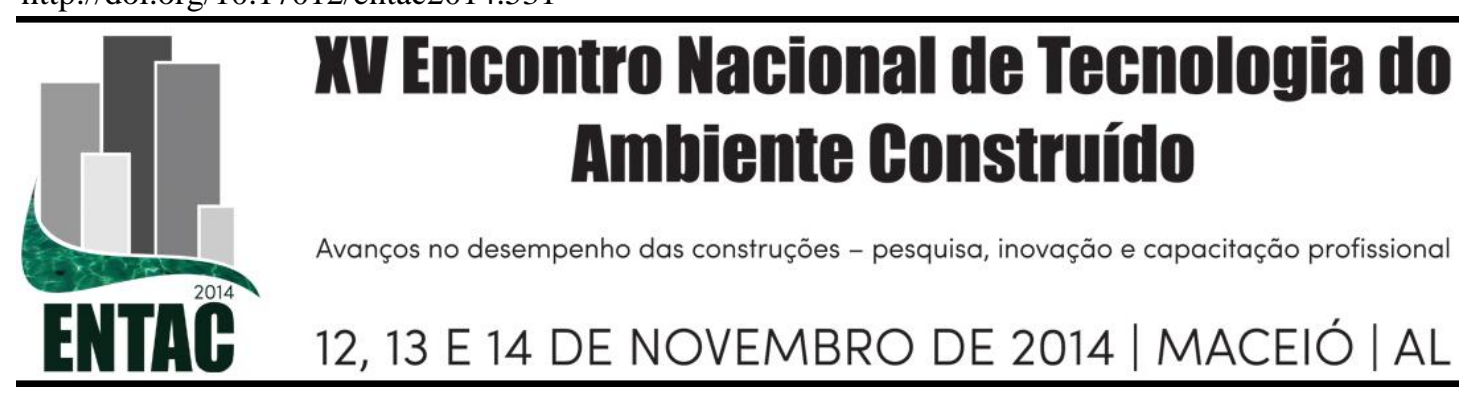

\title{
HABITAÇÃO DE INTERESSE SOCIAL: MUTABILIDADE E CERTIFICAÇÃO
}

\author{
PEREIRA, Márcio da Costa \\ UFS - Universidade Federal de Sergipe, e-mail: marcio.cp@terra.com.br
}

O presente artigo é fruto da tese de doutorado defendida pelo autor e investiga o conceito de mutabilidade com vistas a contribuir para o processo e a análise de projetos de Habitação de Interesse Social e seu desempenho ambiental. O estudo de caso do Conjunto Habitacional Zezinho Magalhães Prado (CECAP) e o estudo documental do debate para a apresentação do projeto realizado no ano de 1968, pelos arquitetos Vilanova Artigas, Fabio Penteado e Paulo Mendes da Rocha, teve por objetivo identificar a aplicação dos conceitos de mutabilidade abordados e compará-los aos critérios de avaliação das certificações que vigoram no setor Habitacional (Casa Azul e AQUA). Por fim, legibilidade e flexibilidade são novos critérios propostos para que, incorporados nos processos de certificação de empreendimentos de interesse social, venham a colaborar na perpetuação do desempenho ambiental conquistado pelo sistema edificado. Acredita-se que conceitos e critérios relacionados à mutabilidade têm afinidade com o desempenho ambiental e que podem vir a colaborar no processo e na qualidade de futuros projetos de Habitação de Interesse Social. Pode-se dizer que a proposta da presente pesquisa alinha-se à de autores e arquitetos que almejam o alto desempenho ambiental dos empreendimentos de interesse social.

Palavras-chave: Conjuntos habitacionais, mutabilidade, meio ambiente.

\begin{abstract}
This article is the result of the doctoral thesis defended by the author and investigates the concept of mutability in order to contribute to the process and project analysis of Social Housing and environmental performance. The case study of the Housing Complex "Zezinho Magalhães Prado" (CECAP) and documentary study of the debate for the presentation of the project conducted in 1968 by the architects Vilanova Artigas , Fabio Penteado and Paulo Mendes da Rocha, aimed to identify the application of concepts as mutability discussed and compare to the evaluation criteria of the certifications that apply in Housing sector ( Casa Azul and AQUA ). Finally, mutability and flexibility are proposed as a new criteria that incorporated in the certification processes of projects of social interest, will collaborate in the perpetuation of environmental performance achieved by the built system. It is believed that concepts and criteria related to the mutability have an affinity for environmental performance and that may collaborate in the process and quality of future projects of Social Housing. It can be said that the proposal of this research aligns to the authors and architects who crave the high environmental performance of projects of social interest.
\end{abstract}

Keywords: Housing, mutability, environment. 


\section{INTRODUÇÃO}

A sociedade da informação é fluida e desliza. Este deslizar pelas mais variadas áreas do conhecimento abriu portas para uma abordagem sistêmica e interdependente da arquitetura. A casa contemporânea abriga um homem cujas necessidades estão ao sabor de uma sociedade múltipla e em constante transformação. Não existe mais o objeto que perdura, mas processos que para perdurarem precisam encontrar ambientes que os absorvam. A arquitetura firme, rígida e permanente sente dificuldade em adequar-se ao ambiente mutável das cidades e dos indivíduos, precisa de forma ambígua, transformarse para perpetuar e não gerar impacto negativo, entulho e poluição. O sistema arquitetônico tem nova relação com o meio ambiente: não se isola e não se impõe, mas interage, desloca-se, transforma-se.

No discurso de apresentação do projeto arquitetônico do Conjunto Habitacional Zezinho Magalhães Prado realizado no ano de 1968, pelos arquitetos Vilanova Artigas, Fabio Penteado e Paulo Mendes da Rocha, identificamos conceitos de mutabilidade que nos remetem à revisão dos critérios de avaliação das certificações que vigoram no setor Habitacional (AQUA e Casa Azul). Legibilidade e flexibilidade são novos critérios propostos para que, incorporados nos processos de certificação de empreendimentos de interesse social, venham a colaborar na perpetuação do desempenho ambiental preliminarmente conquistado pelo sistema edificado.

\section{O CONJUNTO HABITACIONAL ZEZINHO MAGALHÃES PRADO (CUMBICA)}

O Conjunto Habitacional de Cumbica é, depois de Brasília, a primeira experiência feita no sentido da habitação popular capaz de funcionar em condições humanas $e$ racionais. Esse plano deve ser estimulado por todos que batalham pela solução da habitação no Brasil, cujo déficit chega aos sete milhões de unidades. O Conjunto Habitacional de Cumbica tem 10.600 moradias, não significa muito em termos absolutos, mas é uma experiência que pelo seu funcionamento, sua organização e seus padrões adotados, servirá de exemplo ${ }^{1}$. (REVISTA CASA E JARDIM, 1968)

Parte integrante e ao mesmo tempo questionadora da política habitacional realizada pelo Estado brasileiro a partir da década de 1960, o projeto do Conjunto Habitacional Zezinho Magalhães Prado significou o exercício do ideário modernista, colaborando na sua consolidação e no delineamento dos marcos que nortearam o planejamento das cidades do país, visto estar alinhado ao modelo de ocupação de áreas distantes (padrão periférico de crescimento), sem estrutura e sem acesso aos centros urbanos desenvolvidos. Este padrão de ocupação segue os ditames da ausência da provisão do Estado no que diz respeito à promoção de políticas habitacionais adequadas e de longo alcance socioambiental. Resultado deste processo é que a população de baixa renda criou, por conta própria, as condições necessárias à sua instalação, o que se acentua ainda mais a partir da década de 1930 e teve forte repercussão na qualidade ambiental das cidades brasileiras. Reféns da falta de alternativas econômicas e da especulação imobiliária, esta população busca nas periferias o seu estabelecimento, o que leva a criação de um paradigma representado na relação periferia, casa própria, autoconstrução e degradação ambiental.

O Conjunto Habitacional Zezinho Magalhães, no entanto, parece ser um dos poucos registros em termos de política pública de habitação até essa época, apesar do Brasil já

\footnotetext{
${ }^{1}$ Este artigo publicado em 1968 reproduz a grande expectativa que o projeto gerou na época.
} 
apresentar um déficit habitacional bastante elevado. É, pois, o Banco Nacional de Habitação (BNH) e Caixa Estadual de Casas para o Povo (CECAP) que possibilitam a aquisição de alguns imóveis, ainda que insuficiente e dentro de uma área ainda urbanisticamente incipiente.

\section{ABORDAGEM CONCEITUAL E CRITÉRIOS APLICADOS NO PROJETO}

Em 1968 os arquitetos Vilanova Artigas, Fabio Penteado e Paulo Mendes da Rocha, coordenadores e autores do projeto do Conjunto Habitacional Zezinho Magalhães Prado, e o arquiteto Ruy Gama, da CECAP (Companhia Estadual de Casas Populares) são convidados pelos alunos da FAUUSP a apresentar o projeto do Conjunto Habitacional nesta época ainda em construção ${ }^{2}$. Participou também do debate 0 arquiteto e professor da FAUUSP Candido Malta Filho.

Abordando aspectos importantes do projeto original o debate evidencia a preocupação com temas como flexibilidade e mutabilidade do sistema arquitetônico. O urbanismo aberto incorpora a dimensão temporal, absorvendo transformações sociais e possibilitando a participação ativa dos moradores nas mudanças que serão incorporadas ao projeto original. Coloca-se então em pauta a qualidade deste processo identificado como "laisse-faire" em oposição à constrição imposta, segundo Candido Malta, pelo urbanismo modernista. Esta discussão é extremamente pertinente ao tema da mutabilidade e enfatiza a importância e complexidade das técnicas ou modelos que articulam estes princípios.

Podemos creditar pelo menos parte do êxito do empreendimento à concepção do projeto explicitada pelos arquitetos ${ }^{3}$ que considera a mutabilidade. Apesar do conjunto habitacional não ter sido totalmente finalizado, elementos que podem ser caracterizados como sua estrutura de suporte pode ser responsável pelos seus mais de 40 anos de existência.

A seguir temos a análise do projeto do Conjunto Habitacional Zezinho Magalhães como referencia para identificação de novos critérios de certificação do desempenho ambiental de edificações de interesse social.

\subsection{Legibilidade do sistema arquitetônico}

\subsubsection{Distâncias horizontais/ domínio visual}

Os pilotis têm importante papel na visualização. Este domínio visual ao res do chão proporciona segurança, possibilitando o encontro e aproximando os moradores. Esta aproximação pode ser determinante para a postura participativa nas decisões condominiais, principalmente na proposição de mudanças.

A escala humana é referência constante no relato em que se estabelece um raio de $150 \mathrm{~ms}$, como distância que as crianças andariam até a escola, o adulto até o terminal de ônibus, e esta seria também a distância para "atender um conjunto de atividades comerciais cotidianas" (REVISTA DESENHO, 1972).

\subsubsection{Distâncias verticais / gabarito}

\footnotetext{
${ }^{2}$ Este debate foi publicado pela primeira vez em 1972 na revista Desenho, número 4 editada pelos alunos da FAUUSP.

${ }^{3}$ Debate realizado pelos coordenadores do projeto e os alunos da FAUUSP em 1968.
} 
O domínio espacial é proposto também nas dimensões verticais, visto que o gabarito de quatro pavimentos das edificações proporciona a visualização pelas mães das crianças que brincam nas áreas abertas ao rés do chão entre os blocos e nos espaços entre os pilotis do pavimento térreo.

Estou salientando o aspecto de continuidade, o individuo aí está próximo de sua pequena casa com jardim, num edifício alto ele estaria longe de tudo isto. (REVISTA DESENHO, 1972)

\subsubsection{Organização espacial}

A legibilidade do conjunto é proposta pelos arquitetos também quando analisamos as relações de organização espacial. O sistema de deslocamento com uma clara hierarquia viária e o eixo principal que conecta os principais equipamentos propostos em projeto, formam uma estrutura básica que colabora na compreensão da organização espacial e na localização dos moradores.

A importante integração do conjunto habitacional com o bairro e a cidade é uma premissa que encontra sintonia na "grande área central, aberta" para onde converge "um grande movimento da convivência de toda uma população do entorno estimada entre 100.000 a 200.000 pessoas, ” muito mais do que os próprios 60.000 do conjunto.

Desta forma, nestas grandes áreas centrais, onde se localiza o comércio principal, formara uma convivência dando assim aos moradores uma vida não isolada, evitando que este conjunto se torne uma cidade-dormitório, com profundas dificuldades de solução do problema de bem estar deste grupo. (REVISTA DESENHO, 1972)

\subsubsection{Identidade Cultural}

As freguesias: Reforçando esta aproximação cultural com os moradores, Artigas propõe as freguesias e não superquadras. Este termo de origem portuguesa e familiar à população é uma aproximação com um urbanismo de raízes nacionais.

Na freguesia a densidade de prédios, eu creio, procura não afastar demais das tendências de construção das vilas operárias espontâneas de São Paulo. (REVISTA DESENHO, 1972).

Os setores: Além disto, temos a denominação dos setores com nome de estados brasileiros organizados de acordo com as regiões e a própria orientação do plano geral do conjunto. Na ordem iniciando-se do sul em direção ao norte: Rio Grande do Sul e Santa Catarina, seguidos por Paraná e São Paulo, Rio de Janeiro e Minas Gerais, Espirito Santo e Bahia, Alagoas e Sergipe sucessivamente. Esta orientação espacial e identificação cultural, por sua vez, intensificam o sentimento de pertencimento por parte dos moradores do conjunto habitacional estabelecendo vínculo que acentua a integração social e ambiente favorável à organização social e política.

Esta é uma atitude em relação a própria cultura que não tem uma atitude de malícia mas sim uma intenção de falar linguagem própria. (REVISTA DESENHO, 1972)

As cores: Além do gabarito baixo e dos espaços abertos de lazer e encontro entre os blocos, a composição cromática com cores básicas é importante elemento cultural de identificação e de localização dos setores (condomínios). 
As portarias: As portarias são elementos de reconhecimento dos vários setores. É notória a identidade de cada uma e a participação dos moradores empenhados na originalidade de seus condomínios. Estas intervenções que vêm acontecendo ao longo da existência do Conjunto Habitacional Zezinho Magalhães podem ser talvez, fruto do diálogo entre os moradores que se apropriam do espaço de forma positiva e autônoma.

\title{
3.2 Flexibilidade do sistema arquitetônico
}

\subsubsection{Flexibilidade nos espaços externos}

Paisagismo/áreas verdes: As áreas verdes são parte integrante na concepção do projeto das unidades habitacionais e do traçado urbanístico, não se constituindo elemento agregado ao projeto depois de sua concepção. Este paisagismo bastante generoso representou um forte desafio para os arquitetos que postulavam empregar alta soma de capital na execução destas áreas.

Este grande volume de áreas verdes são espaços que atendem às mais diversificadas atividades no convívio dos moradores. Sua configuração tem se alterado e é peculiar a cada setor do conjunto habitacional.

Espaços entre os blocos: Os espaços entre os blocos e sob os pilotis não têm uma definição clara de uso, permitindo diferentes ocupações.

\begin{abstract}
Para organizar as freguesias a solução sobre pilotis é uma decorrência natural do fato de utilizar as áreas ligadas aos planos de acesso para uma série eventual de atividades muito difíceis de prever, são áreas ligadas a recreação e que conduzem naturalmente às áreas de comércio local da freguesia, aos pontos de ônibus e principalmente às áreas de estacionamento. (REVISTA DESENHO, 1972)
\end{abstract}

As grandes áreas centrais: Fabio Penteado, por sua vez, apresenta o planejamento geral do conjunto habitacional tendo como estrutura básica um sistema composto por um grande espaço aberto que convergiria para áreas "de comércio e outras utilizações [...] as mais generosas possíveis", e que, por outro lado confluiria para as freguesias densamente ocupadas. Estes espaços abertos teriam o importante papel de absorver futuras dinâmicas sociais. A ocupação destas áreas dá-se na medida em que as relações de convivência e apropriação do sistema edificado se consolidam, permitindo a apropriação e participação dos envolvidos no processo de conformação do espaço em transformação.

\subsubsection{Flexibilidade nos espaços Internos}

A planta livre: Espaço interno das edificações sem locação de pilares que poderiam impedir a livre organização dos ambientes (planta flexível) e fechamentos com divisórias removíveis.

As janelas em fita: Associada a planta livre, as janelas em fita permitem que as divisórias tenham maior independência em sua localização.

Armários localizados embaixo e ao longo das janelas: Assim como as janelas em fita, esta disposição dos armários dos quartos e cozinha permitem mudanças na configuração interna dos espaços. 
Núcleo com as áreas molhadas: As áreas molhadas formando um bloco e liberam área para que os ambientes contíguos tenham maior flexibilidade em seu layout.

\section{AS CERTIFICAÇÕES AMBIENTAIS}

É importante ressaltar que o empreendimento habitacional deve ser entendido como um sistema em que os vários elementos que o compõem dialogam entre si e com o meio ambiente, tendo como resultado feedbacks responsáveis por mudanças e pela autonomia do sistema edificado. $\mathrm{O}$ isolamento de um destes elementos pode comprometer $\mathrm{o}$ desempenho ambiental do sistema como um todo. Portanto, os critérios que compõem e avaliam o sistema devem garantir o diálogo entre as várias partes que compõem o todo.

Diferentemente das certificações AQUA e Casa Azul, que são direcionadas para empreendimentos de todas as modalidades de habitação, as recomendações de medidas e instrumentos de gestão desenvolvidos pelo programa de Tecnologia de Habitação (Habitare) são especificas para Habitação de Interesse Social. Esta observação é relevante se considerarmos que as habitações de Interesse Social tem o estado como financiador e empreendedor, ficando a iniciativa privada com a responsabilidade da incorporação e construção dos empreendimentos aprovados ou licitados. O mutuario é inscrito em um cadastro único mediante o atendimento de condições estabelecidas ( renda máxima e não possuir imóvel próprio) e o grupo de moradores beneficiados é formado antes da execução da obra. Portanto, um importante diferencial quando falamos de empreendimentos de Interesse social, é que já existe formado ou pode ser identificado, um grupo de moradores que ocuparão os imoveis desde o inicio do empreendimento. A participação dos moradores e comunidade e os critérios para análise dos projetos podem, deste modo, ser aplicados desde as fases iniciais de concepção do empreendimento .

Reconhecem-se os conceitos de mudança e de interdependência, advindos da cibernética e do pensamento sistêmico no projeto desenvolvido e defendido por Artigas e equipe técnica da CECAP para o projeto do Conjunto Habitacional Zezinho Magalhães. Emergem desta análise dois critérios que constituem o suporte do sistema edificado e que podem ser identificados como fundamentais para a perpetuação do desempenho ambiental positivo do conjunto habitacional: legibilidade e flexibilidade.

As certificações ambientais cumprem importante papel sistematizando e definindo critérios para análise de projetos arquitetônicos que devem agregar qualidade ao ambiente em que se inserem. Analisando comparativamente as certificações internacionais atuantes no Brasil e que foram de alguma forma modelo para os únicos selos que certificam as habitações e os conjuntos habitacionais, Processo AQUA e o Selo Casa Azul, reconhece-se a necessidade de incorporar critérios relacionados ao conceito de mutabilidade para garantir o contínuo processo de qualificação ambiental do sistema edificado, diluindo fronteiras e intensificando seu diálogo com os vários agentes intervenientes. Segundo Ashby(1957), estas mudanças serão efetivas e determinantes a partir do momento em que os atores envolvidos compreendem e apreendem os elementos envolvidos na dinâmica (mudança de segunda ordem), senão, "transformações sem fim" ou reformas, podem determinar um fluxo indevido de emissões sem existir uma real e positiva mudança no sistema. Esta afirmação, de certa forma, já pode ser evidenciada em projetos certificados, mas que, por não incorporarem a mutabilidade como critério, após a entrega do empreendimento redundam em sistemas 
edificados que nada, ou pouco resguardam do desempenho ambiental que os certificaram.

A participação de cada um destes atores é fundamental para que o diálogo se estabeleça, e os feedbacks sejam absorvidos pelo sistema. No caso do objeto em estudo, Habitação de Interesse Social, a participação do morador e comunidade desde o início do projeto será responsável pela qualidade do desempenho do sistema, uma vez que os construtores e empreendedores ao entregarem a "obra" perderão vínculo com o empreendimento e os moradores e comunidade permanecerão dialogando com o meio ambiente. Portanto e importante sistematizar estes critérios e propô-los como parte do escopo da metodologia de análise dos empreendimentos que buscam o alto desempenho ambiental.

\section{CONSIDERAÇÕES FINAIS}

Dois conceitos dão suporte a mutabilidade do sistema: a legibilidade com o papel de viabilizar mudanças e a flexibilidade que absorve as mudanças.O grau de legibilidade do sistema pode ser averiguado a partir de propostas projetuais como distâncias horizontais, domínio visual,distâncias verticais, gabarito, identidade cultural e organização espacial (eixos, hierarquia nos sistemas de circulação, simetria e ritmo), e o grau de flexibilidade a partir da proposição de áreas externas flexíveis (áreas verdes, espaços que permitam usos diversificados) e áreas internas flexíveis (uso de tecnologias que permitam a reorganização dos espaços).

Estes dois critérios sugeridos para a avaliação da certificação ambiental, flexibilidade e legibilidade, associados ao processo participativo, são relevantes para o desempenho positivo do sistema arquitetônico e a eles pode-se creditar grande parte das ações propostas pelos moradores, seja no âmbito das interdependências internas ou na interdependência com o meio ambiente que o circunda, tanto de dentro para fora como de fora para dentro. Percebe-se como resultado desta dinâmica, que o Conjunto Habitacional Zezinho Magalhães Prado "absorveu" e foi "absorvido" pela cidade de Guarulhos, de tal forma que hoje se transformou em vetor de desenvolvimento regional e qualidade de vida.

\section{REFERÊNCIAS}

ADDINGTON, D. Michelle, SCHODEK, Daniel L. Smart materials and technologies. Oxford: Elsevier,2006.

ALEXANDER, Christopher ... [et al.]. A pattern language : towns, buildings, construction. New York; Oxford: Oxford University Press. 1977.

ASHBY, W. Ross . An introduction to cybernetics. London: CHAPMAN \& HALL LTD, 1957.

BARROS, Raquel Regina M.P. Habitação coletiva: a inclusão de conceitos humanizadores no processo de projeto. Tese de Doutorado UNICAMP, 2008.

CERÁVOLO, Fabiana. A pré fabricação em concreto armado aplicada a conjuntos habitacionais no brasil: o caso do conjunto habitacional zezinho magalhães prado. Dissertação (Mestrado) EESC/USP : São Carlos, 2007. 
CHING, Francis D.K. Arquitetura: forma, espaço e ordem. São Paulo: Martins Fontes, 1998.

CUNHA, Gabriel Rodrigues. Uma análise da produção de Artigas entre os anos de 1967 e 1976. Dissertação (Mestrado em Arquitetutra e Urbanismo) EESC/USP, São Carlos, 2009.

FICHER, Sylvia. Subsídios para um estudo do Conjunto Habitacional Zezinho Magalhães Prado. Monografia Trabalho Final de Graduação FAUUSP: 1972

FREITAS, Carlos Geraldo Luz de et. al. Habitação e meio ambiente: abordagem integrada em empreendimentos de interesse social. São Paulo: Instituto de Pesquisas Tecnologicas do Estado de São Paulo IPT: 2001.

GUERRA, Tiago Cavalcante. CECAP Guarulhos: histórias, identidades e memórias. São Paulo : Scortecci, 2010

HABRAKEN, N. John. Supports: an alternative to mass housing, Urban International Press, UK : Edited by Jonathan Teicher, 1999.

HOFFMAN ,Alexander von. ARTIGO : "Why they built pruitt-igoe." Taubman Center Publications. Disponivel em :http://www.soc.iastate.edu/sapp/pruittigoe.html Acesso em : $10 / 03 / 2010$

ISSAC, Solimar Mendes. Parque CECAP Guarulhos: transformação urbana. Dissertação ( Mestrado). São Paulo, FAUUSP: 2007.

JOHN, Wanderley M. Construção e desenvolvimento sustentável. Revista qualidade na construção. São Paulo : SINDUSCON, n23 ano III,2000.

JOHN, Wanderley Moacyr PRADO Racine Tadeu Araujo ( organizadores) Boas práticas para habitação mais sustentável. São Paulo: Páginas \& letras - Editora e Gráfica,2010.

KRONENBURG, Robert. Flexible : architecture that responds to change. Londres: Blume, 2007.

MONTANER, Josep Maria. Sistemas arquitectónicos contemporâneos. Barcelona: Gustavo Gilli,2008

MORIN, Edgar . A inteligência da complexidade. São Paulo: Peirópolis, 2000.

MORIN, Edgar. Introdução ao pensamento complexo. Porto Alegre: Sulina,2007.

PATEMAN, Carole. Participation and democratic theory . Cambridge: Cambridge

University Press, 1970

REVISTA ACRÓPOLE, São Paulo, nº 372, Abril 1970.

REVISTA CASA E JARDIM, São Paulo nº 160, Maio 1968.

REVISTA DESENHO, São Paulo no 4, FAUUSP, 1972

SANTOS, Carlos José Ferreira dos. Guarulhos : espaços identitários sob a mundialização. Tese ( Doutorado em Arquitetura e Urbanismo) FAU USP. 2003

SLESSOR, Catherine. Eco-tech : susteinable arquitecture and high tecnology. United Kingdom : Thames \& Hudson, 1997 
WINES, James. Green architecture. London: Taschen,2000.

YEANG, Ken. Proyectar com la naturaleza. Barcelona: G. Gili .1999. 